Interdisciplinary Studies of Complex Systems

No. 17 (2020) 83-101

(C) O. Romanovskyi, Yu. Romanovska

https://doi.org/10.31392/iscs.2020.17.083

\title{
HighER EDUCATION INNOVATICS AS THE NEWEST INTERDISCIPLINARY DIRECTION OF HIGHER SCHOOL AND HIGHER EDUCATION SCIENCE
}

\author{
Oleksandr Romanovskyi ${ }^{1}$, Yuliia Romanovska ${ }^{2}$
}

\begin{abstract}
For real European integration of Ukraine and increasing the scientific level of the Ukrainian higher education, the introduction of innovative methods and techniques is necessary. For a correct understanding of the innovative directions of reforming higher education, it is necessary to create a scientific apparatus that combines the theory and practice of innovative development of higher education and the entire system of higher education. Authors propose to introduce a new scientific direction in the sphere of higher education with a new scientific term — "Innovatics of higher education" or "higher education innovatics".

The theoretical foundations and practical provisions of the new scientific direction in the sphere of higher education - the innovatics in higher education includes a complex of innovative changes in such inherent in higher education types of activities as: teaching, training, study; scientific and $\mathrm{R} \& \mathrm{D}$ activities, new technic and technologies development, construction and design creativity; cultural and moral development, upbringing of human values; education of honesty and justice, patriotism and peacefulness; instilling love and tolerance for one's neighbor, mercy and charity, compassion; engineering, technical, informational activities; financial and economic support of the educational process and R\&D, operating and business expenses, development and expansion of activities; inventive and patent-licensing activities, technology transfer; academic or university entrepreneurship; sports, recreational, festive and extracurricular activities; and other types of activities of universities, colleges and other institutions related / involved / associated with higher education.

Thus, innovatics in higher education (as the complex of innovations in the whole sphere of higher education) includes innovative changes in almost all areas of higher education to enhance and/or improve the quality training of professionally prepared and responsible citizens of the modern community and for development of university R \& D. These can be useful for reforming the national higher education system of Ukraine and for the development of a new scientific direction in the field of higher education.
\end{abstract}

Keywords: higher education; innovation in university education, higher education innovatics, higher education reforming, academic or university entrepreneurship

\footnotetext{
${ }^{1}$ Ukrainian-American Concordia University (UACU), Kyiv, Ukraine oleksandr.romanovskyi@uacu.edu.ua, https://orcid.org/0000-0002-3618-2999

2 National Pedagogical Dragomanov University, Kyiv, Ukraine yuliia.romanovska@uacu.edu.ua, https://orcid.org/0000-0002-0207-3348
} 
Actuality of theme. The prospect of building a knowledge society with an innovation-oriented type of economy in Ukraine requires a profound reform of the humanitarian sphere of the national economy, innovative development of the higher education system, science and scientific-technology activity. This should be done on the basis of a reasonable combination of best foreign experience with national traditions. Considering the priority of the state policy of innovative development of the higher education sector, introduction of innovative entrepreneurship of different types and legal forms, the basis for economic reform and the main lever in the new model of the domestic economy is the activation of all types of entrepreneurship, including innovative academic (or university) entrepreneurship, as an integrated socio-economic process. The accelerated development of national higher education, science, innovative technologies and innovative entrepreneurship is especially relevant in the period of search for new economic models and strategies that will facilitate the accelerated development of the domestic economic system. It is important to further improve the institutional environment for innovation in Ukraine, as well as to unlock and realize the entrepreneurial potential of the nation as a major institutional resource for developing a market economy, achieving higher competitiveness and raising social standards.

Statement of the problem. In the context of the spread of market mechanisms in all spheres of humanitarian activity of mankind, the emergence of the phenomenon of academic or university entrepreneurship, commercialization of knowledge and results of universities and scientific institutions R\&D, it is advisable to create and develop an innovative direction of interdisciplinary science in the field of higher school and the higher education system as a whole - the "Innovatics in higher education" (or the "Higher education innovatics").

Innovatics in higher education is called upon to develop and scientifically substantiate the theory and practice of innovative development in the field of higher education, to promote the practical implementation of a complex of innovative changes in the higher education system, to determine the necessary directions and mechanisms for the innovative transformation of both the higher education industry and its subjects - higher educational institutions, institutions and bodies related to higher education.

Analysis of recent studies and publications. A significant number of publications are devoted to the problems of introducing innovations in the higher education system. For example, the book [1] examines the influences of governmental regulation on the behavior of higher education institutions in the Netherlands, West Germany and France with respect to designing and implementing innovations in curricula. It's describes two basic general governmental strategies (rational planning and control versus self-regulation) and an inventory of the various instruments a government may use to influence society and addresses the subject of innovations in higher education through an analysis of the literature on the subject.

The paper [2] reviews trends in higher education, characterizing both the current learning environments in pharmacy education as well as a vision for future learning environments, and outlines a strategy for successful implemen- 
tation of innovations in educational delivery. The following 3 areas of focus are addressed: a) rejecting the use of the majority of classroom time for the simple transmission of factual information to students; b) challenging students to think critically, communicate lucidly, and synthesize broadly in order to solve problems; and c) adopting a philosophy of "evidence-based education" as a core construct of instructional innovation and reform.

In the work [3] the authors emphasize that higher education is currently confronted by global forces that necessitate innovative research, innovative pedagogies, and innovative organizational structures. For these reasons, authors suggest that a theoretical understanding of innovation is imperative for higher education's continued development in the twenty-first century. Grounded in the innovation interdisciplinary literature from a variety of academic disciplines, this publication outlines a conceptual framework in five sections. First, there are delineated four imminent trends in higher education that may compel innovative responses. Afterwards, working definitions of creativity, innovation, and entrepreneurship are generated through the clarification of several terms that are related to innovation. Next, there are discussed the concepts of sustainable and disruptive innovation by demonstrating how change and innovation has been a consistent fixture of higher education since its inception. Then, there are considered three dimensions of innovation - diversity, intrinsic motivation, and autonomy - that positively impact the ability of individuals working within higher education to be innovative. Finally, there are addressed three additional concepts - time, efficiency, and trust - that are important for a thorough consideration of innovation within an institutional setting.

This background report to the second Global Education Industry Summit, held in Jerusalem on 26-27 September 2016, [4] covers the available evidence on innovation in education, the impact of digital technologies on teaching and learning, and the role of digital skills and the education industries in the process of innovation, using data from OECD surveys. Innovation will be essential to bring about qualitative changes in education, as opposed to the quantitative expansion seen so far. These changes are needed to increase efficiency and improve the quality and equity of learning opportunities. Education can also foster innovation in society at large by developing the right skills to nurture it. These skills, including critical thinking, creativity and imagination, can be fostered through appropriate teaching, and practices such as entrepreneurship education. Governments should develop smart innovation strategies for education with the right policy mix to give meaning and purpose to innovation, including creating an innovation-friendly culture. Understanding the education industries better, including their market structures and innovation processes, would help to create a more mature relationship with the education sector. Innovation in the industry - which develops the products and services that could drive innovation in schools - does not happen in isolation from what is happening in the education sector. Only when there is an innovation-friendly culture in education systems, supported by an innovation-friendly business environment and policies, will industries start to engage in risk-intensive research and development. Governments can support this by fostering a climate of entrepreneurship and innovation in education.

Also, many publications are devoted to innovative transformations in higher education institutions under the influence of the spread of market re- 
lations in humanitarian spheres of society, and the emergence in the second half of the twentieth century a new type of capitalist relations in the scientific, intellectual, technological and educational spheres - academic capitalism [5]. A real opportunity to commercialize $R \& D$ results emerged, leading to rapid development of university and academic science and technology [6].

Theoretical research and practical recommendations in the field of creating innovative entrepreneurial universities, pioneer in this field, Burton R. Clark and the theoretician and practice of innovative development of society according to the "triple helix model" Henry Etzkowitz [10-15] became the impetus for the development of innovative university entrepreneurship and a significant increase in the role of higher educational institutions in the innovative development of society. In article [16] is shown how HEIs driven to digital transformation today.

Against the background of the existence of different approaches, methods, types and types of innovations that exist in the system of higher (university) education, there is still no unified scientific theoretical base, generalization and description of the tasks of complex innovative changes in this field, leading to dramatic improvements and reforms in higher education. Such a lacking scientific theoretical and practical basis for the systematization, classification, justification and further development of innovative activities in the field of higher education can become an applied scientific direction in the science of higher education - the "innovatics in higher education" or "higher education innovatics".

The purpose of article. The main goal of the article is to introduce the concept of higher education innovatics into scientific circulation, to define its tasks as an applied scientific direction in the field of higher education of Ukraine, to identify features and directions of application.

In this study will be used such research methods, as: dialectical approach for analyzing and comprehending the content and special characteristics of the innovative development of higher education on the basis of new phenomena of academic capitalism, university (academic) entrepreneurship, as economic categories in the system of socio-economic relations and relations of the holistic economic system of the modern knowledge society; abstraction methods, system-structural and theoretical-informational approaches will be used to investigate the conditions of formation of new innovative forms of university (academic) entrepreneurship, peculiarities and essence of university business activity and its influence on the financial stability of higher education institutions; the methods of analysis and synthesis will be used to investigate individual innovative approaches and technologies in higher education and to form a holistic picture of the complex innovation activity of the subjects, objects and system of higher education as a whole. The research methodology included a critical study and awareness of the concept of innovation in higher education; analysis of literary sources, including electronic and computer aids; comparing and checking the feasibility or necessity of introducing different types of innovations, analyzing their effectiveness and the possibility of dissemination and implementation to objects and subjects of the higher education system; forecasting ways of formation of new innovative approaches, methods and technologies; integration of research results and formation of scientific theoretical, 
methodological and practical provisions of the new direction - the higher education innovatics.

Presentation of the main research material. Because of the conducted research, identification and analysis of economic mechanisms of innovative development of higher education, which are the effective factor in improving the efficiency and management of the national, in our case - Ukrainian economy the authors would like to make the following theoretical conclusions.

1. Innovative development of higher education is a state-oriented restructuring and implementation of qualitatively new transformational changes in higher education and science in the humanitarian system of a single national economic complex - the Joint national economy complexes of Ukraine (JNECU) based on effective activation and stimulation of innovative activity in this sphere.

2. The essence of innovative development of higher education is a social systemic technical and economic process, characterized by the following features:

- Purpose - innovative reform of higher education;

- Object - educational and scientific branch of the humanitarian sphere of the national economy, which includes innovative universities, oriented towards university (academic) entrepreneurship;

- Implementation of:

- establishing innovative business-type universities; enhancing the role of intellectual entrepreneurship in higher education as a driver of economic growth on the basis of the spread of academic (university) entrepreneurship;

- innovative economic mechanisms development;

- the necessary conditions of public support and favorable legislative framework for innovative academic (university) entrepreneurship;

- availability of scientific and pedagogical, engineering and technical staff and students ready for business.

At the same time, innovations in higher education are complex and have the characteristics of product, technologies, market and organization.

3. The theoretical foundations of state-oriented innovation development of higher education are:

- economic science;

- theory of entrepreneurship and economic development;

- theory of innovative development;

- theory of market economy;

- theory of public administration;

- theory of state management of economy;

- international economics;

- theories of humanitarian development and humanitarian policy of the state;

- theory and practice of higher education;

- economics of higher education; 
- the theory of "academic capitalism";

- the theory of "academic (university) entrepreneurship" and theoretical substantiation of the role of innovative research-oriented entrepreneurial universities as accelerators of economic growth.

The organizational and methodological foundations of innovative development of higher education based on widespread introduction of university entrepreneurship, as the main moderator of innovative transformations in the humanitarian policy and non-industrial - nonmaterial sphere are:

- state policy in the field of innovation development of the branches of the JNECU;

- state, regional and local legislative regulations and rules for higher education and entrepreneurship systems (as a component of all four sectors of the country's economy);

- development and implementation of innovative models of entrepreneurship, including university (academic) entrepreneurship and granting the rights of universities and research institutes to commercialize the results of $\mathrm{R} \& \mathrm{D}$ performed at the expense of budget financing;

- financial and tax incentives for the development of university (academic) entrepreneurship;

- definition of directions of development of universities and their tasks in the socio-economic development of countries, regions and local communities;

- organizational and methodological decisions of university owners and staff regarding participation in academic business activity;

- social factors influence.

A very important step is uniting activities of universities and research institutions of the National Academy of Sciences (NAS) of Ukraine, sectoral research institutes and scientific laboratories on the basis of merging into educational and scientific-industrial complexes (techno-parks) with the formation of scientific-industrial techno-polis. The JNECU has a certain structure, which presupposes the presence of components and connections between them. Its main components are two spheres: the productive sphere in which material goods are produced, and the service sector (non-productive sphere), which mostly provides services to the population.

The conceptual foundations of innovative development of higher education comprise on:

- H. Etzkowitz's concept of innovative development of society by the "triple helix" model [10-13], which is successfully used in many developed countries (USA, UK, Canada, Australia, Japan, Germany, Sweden and many other countries of the EU) and in the developing world (China, Russia, Brazil, some other South American countries, etc.);

- B. Clark's concept of transformational changes of conventional universities into innovative universities focused on in-house entrepreneurial activities ("business universities") [7-9], which has been validated in higher education systems in many countries of different continents (North and South America, the United States of America, Western Europe, Japan, Africa). 
- practical principles (and necessary conditions) of innovative development of higher education, which means effective university entrepreneurship, as the main factor of innovative transformations in educational and scientific activity of society is connected with public entrepreneurial mentality and national recognition of the role of universities in economic, scientific and technological development of countries. A favorable legislation to support academic entrepreneurship and commercialization of $\mathrm{R} \& \mathrm{D}$ results is also necessary and very important.

- the willingness and readiness of the teams of research and other types of universities to academic entrepreneurship; the presence of entrepreneurship leaders and employees of the university, the necessary entrepreneurial traits of character, knowledge and skills in the field of entrepreneurship;

- the existence of supply and demand markets in the field of academic (educational, scientific and engineering);

- the awareness of the necessary transformational conditions by the university communities (according to B. Clark), innovation policy and innovation relations, as well as corporate entrepreneurial culture;

- the cooperation of universities with industry and business with the effective support of governments; economic efficiency of university (academic) entrepreneurship;

- the availability of diversified sources of financial revenues to the HEI budget;

- the endowment institute;

- the commercialization of $\mathrm{R} \& \mathrm{D}$ results, transfer of new and introduction of new technologies, creation of spin-offs and start-ups of companies (small enterprises) with the direct participation of employees, students and graduates of universities.

4. The prerequisites for innovative changes in higher education are the formation and development of university entrepreneurship under the influence on:

- the globalization processes of society transformation;

- the new societal challenges to raise the level of education of the labor resources and the quality of their professional qualifications due to the sharp increase in knowledge and significant complication of production and technological processes;

- the reforming higher education systems and changing the paradigm of training specialists in accordance with current socio-economic needs of society and market requirements;

- the reduction of budget funding for universities, colleges and other types of universities;

- the need for competitive financial support for highly qualified university staff, statutory activities of universities, the implementation of fundamental and applied research and development of the material and technical base and necessary infrastructure of universities;

- the extending the mechanisms and foundations of a market economy to humanitarian spheres. 
The preconditions for such changes are:

- the new expanded role of universities and other types of universities and the need for their financial independence;

- enhancing the socially beneficial role of entrepreneurship and its extension to all spheres of human activity;

- the improving and disseminating business education and more.

5. The main task of innovative development of higher education in any country is creation of the necessary conditions for a direct purposeful organizationaleconomic, scientific-educational and engineering-technological activity aimed at the formation of a knowledge society with an innovation-oriented type of economy of the state.

The main tasks of innovative academic (university) entrepreneurship are:

- production and capitalization of new knowledge;

- quality implementation of R\&D with further effective commercialization of the results;

- widespread dissemination (transfer) of new knowledge, R\&D results and advanced technologies;

- development of innovation activities of universities;

- development, implementation of concepts and implementation of methods, technologies and techniques of innovative economic and social development of local communities, regions, country;

- contribution to national economic growth, national GDP and the competitiveness of countries' economies; development and dissemination of a new type of entrepreneurial activity in the intellectual sphereacademic entrepreneurship in universities;

- promoting effective entrepreneurship education and entrepreneurship education development;

- promotion of financial self-sufficiency and independence of higher education institutions, raising the level of material support of teaching staff and other employees of higher education institutions.

6. It is advisable to consider the ways to further innovative development of the higher education:

- introduction of the institute of innovative academic (university) entrepreneurship;

- development of a sector focused on academic entrepreneurship of nonprofit and for-profit universities with the participation of private capital;

- development of an endowment institute for the financial support of leading research universities in entrepreneurship;

- granting at the legislative level full autonomy of universities for independent choice of development strategies, directions of statutory activity and achievement of financial independence;

- introduction of the institute of state (budgetary) and private (independent) project financing in the field of higher education, organization of state support for cooperation between universities and industry (according to the model of "Triple helix" by H.Etzkowitz). 
7. "Academic capitalism" [5-6] and "university entrepreneurship" [7-13] can be defined as economic categories that have their own characteristic, related to the capitalization and commercialization of intellectual products - new knowledge, technologies, teaching methods. "Academic capitalism" is a new economic and social environment in which scientific institutions and systems of higher education and all universities of the world in the late XX - early XXI centuries exist, and which includes "university entrepreneurship" as an intellectual type of entrepreneurial activity of researchers, professors - teaching staff, engineers, technologists, designers and university students.

It is necessary to study, summarize experience and describe the theoretical foundations and practical provisions of innovation activity in the field of higher education (we mean - the university education) from the already known innovative activity in the field of higher education. The theoretical foundations and practical provisions of innovation activity in the field of higher (university) education it is advisable to distinguish as a separate scientific direction in the sphere or field (sector) of higher education. Authors propose to introduce a new scientific direction in the sphere or field (sector) of higher education with a new scientific term - "Innovatics of higher education" or "higher education innovatics". The use of the term "higher education innovatics" may be appropriate to designate a separate scientific direction in the field (or system, or field, or sector) of higher education by analogy with the scientific areas "Fundamentals of Higher Education", "Theory and Practice of Higher Education", "Economics of higher education" etc. However, at the same time - differ from other scientific areas in the field of innovation (innovative activity).

By definition, the theoretical foundations and practical provisions of the new scientific direction in the sphere of higher education - the innovatics in higher education has to include a complex of innovative changes in such inherent in higher education types of activities as:

- teaching, training, study;

- scientific and R\&D activities, new technic and technologies development, construction and design creativity;

- cultural and moral development, upbringing of human values;

- education of honesty and justice, patriotism and peacefulness;

- instilling love and tolerance for one's neighbor, mercy and charity, compassion;

- engineering, technical, informational activities;

- financial and economic support of the educational process and R\&D, operating and business expenses, development and expansion of activities;

- inventive and patent-licensing activities, technology transfer;

- academic or university entrepreneurship;

- sports, recreational, festive and extracurricular activities;

- and other types of activities of universities, colleges and other institutions related / involved / associated with higher education.

Thus, innovatics in higher education (as the complex of innovations in the whale sphere of higher education) includes innovative changes in almost 
all areas of higher education to enhance and/or improve the quality training of professionally prepared and responsible citizens of the modern community and for development of university R \& D. These can be useful for reforming the national higher education system of Ukraine and for the development of a new scientific direction in the field of higher education.

We have researched and developed the foundations and concepts the "innovatics" in higher education based on general theories of innovation activity of other spheres and fields of human activity. Innovatics in higher education should comprehensively promote the following activities:

- to study the laws of the processes of development and formation of innovations, introducing new solutions to existing problems;

- to research change management mechanisms;

- to study and propose ways to overcome resistance to innovations in the field of higher education, pedagogical, scientific and engineering activities,

- to develop mechanisms for human adaptation to innovative changes,

- to study the use and dissemination of innovative flows,

- to promote and prove the benefits of innovation, the impact of innovation on the development of competition in higher education and science, as well as on accelerating and improving the development of higher education and science in the state as a whole.

Authors think that the subject of higher education innovatatics has to be the principles, laws and consistent pattern of innovation processes in higher education and science as a socio-economic system of humanitarian policy of the JNECU. Including models and methods of description, research, organization and management of innovative activities (educational, pedagogical, scientific, technical, organizational and economic) at the macro level (national innovation system of higher education and science), meso level (industry and regional innovation systems and innovation clusters of education and science), and micro levels (strategies for innovative development of individual HEIs, scientific institutions, enterprises and organizations of higher education and science). In higher education, innovatatics, as a scientific field, can be distinguished two complementary components: theoretical innovatatics and applied.

Theoretical innovations of higher education should solve problems of creation and development of scientific methodology of innovation in higher education and science, theoretical problems of synthesis of innovatively complex organizational and technical systems (new knowledge, ideas, pedagogical methods, techniques, technologies, inventions, discoveries, etc.). Applied higher education innovatatics refers to the direction of innovation in solving problems of planning, organizing and implementing innovations in the higher education system. The task of applied innovations of higher education should be to solve the organizational and legal issues of innovation, the creation and implementation of innovative projects, etc.

The expected best result of innovative research and its implementation in the field of higher education is the achievement of practical effect for the welfare of the state, humanity as a whole.

The main areas or sections of higher education innovatatics in the field of humanitarian policy of the JNECU including intangible production, which is 
a sphere of social production in which are produced intangible services: retail, public catering, passenger transport and communication (serving the public), household services, health care, etc., and spiritual values: education, upbringing, culture, art, etc. should be:

- theoretical foundations of pedagogical (pedagogical innovations), scientific and technical (innovations of scientific and technological revolution) and organizational and economic innovation activity in the higher education system;

- theoretical foundations for the formation of innovative corporate entrepreneurial culture in the higher education system;

- models and modeling (including economic) of innovation processes;

- organization and management of innovation development and innovation activity;

- state regulation of innovation activity;

- management of innovative business, incl. - university or academic entrepreneurship, spin-offs and start-ups;

- management of innovative projects;

- management of investments in innovative projects;

- commercialization of the results of scientific, technical and creative activities;

- human resources management in the process of innovative development of socio-economic system;

- managing risks in innovation;

- Technical marketing (early-stage marketing of a product or technology);

- logistics of innovation processes;

- managment of intellectual property.

The innovative development of higher education can be understand as state-directed structural restructuring and the implementation of qualitatively new transformational transformations in the field of higher education and science in the humanitarian policy system of the JNECU based on the effective activation and stimulation of innovative activity in this area.

Transformations can be carrying out based on the latest scientific achievements and theoretical and methodological foundations, under the clear legislative and executive control of state and economic bodies, in an effective system of organization and management. The strategy of structural adjustment of the economy of higher education can be based on the principles of self-organization and the application of theoretical and practical achievements of economic science.

Innovative activity in the field of higher education and science is the process of creating, implementing and disseminating in the practice of higher education, scientific and engineering activities of new ideas, means, scientific, engineering, pedagogical, organizational and managerial and economic methods and technologies. Because of which, the achievement indicators of the structural components of the higher education system, scientific and technical activities and scientific services are increased and its transition to a qualitatively higher level takes place. 
This activity:

- is based on theoretical and methodological principles of pedagogical, scientific, technical and economic innovation of higher education;

- is aimed at transformational transformations of the higher education system;

- aims at the innovative development of higher education and science;

- is carried out to solve the strategic task of the humanitarian sphere of the JNECU - further building the information society of knowledge with an innovation-oriented type of economy.

Innovations in higher education and science are related to:

- the formation and accumulation of new knowledge;

- the use and commercialization of research and development results;

- the transformation of $\mathrm{R} \& \mathrm{D}$, other scientific and technological developments into new or improved products, technologies, services introduced on the market, into a new or improved technological process used in practice, or a new approach to social services;

- the formation and accumulation of intellectual capital and the formation of human capital;

- the formation of entrepreneurial mentality and corporate entrepreneurial culture in subjects of innovation activity in the higher education system;

- the using new tools, methods and technologies to accelerate the economic growth of society.

The objects of innovation activity in the field of higher education and science are obviously:

- the innovative programs and projects;

- the new knowledge and intellectual products, educational and scientific services;

- the infrastructure of higher education and science in the humanitarian system of JNECU, university (academic) and intellectual entrepreneurship;

- the organizational and technical decisions of an economic, administrative, commercial or other (non-productive) nature that substantially improve the structure and quality of the humanitarian policy of the JNECU (non-production and social sphere);

- the new experimental designs and innovative solutions of engineering and technical character, innovative technologies for production of new products (services);

- the mechanisms of formation:

- the markets for educational and scientific services;

- the manpower required qualifications,

- the education of employees of the entrepreneurial mentality and integrated corporate entrepreneurial culture;

- the cooperation of the triad "University - Industry (Business) — Government (State)". 
The subjects of innovation activity in the field of higher education and science are individuals or legal entities (HEIs, scientific institutions, structural units of the educational and scientific system), which carry out innovative activity or attract property and intellectual values, invest their own or borrowed funds in the implementation of innovative JNECU humanitarian policy projects.

Innovation in higher education and science is designed to produce an innovative product, new service, innovative technology, methodology or new solution. An innovative product is a research or experimental design development of a new technology (including information technology) or products with the production of experimental designs or experimental batches.

Innovative activities in higher education directly affect the intellectual and socio-economic development of states. The main task of innovative development of the higher education sphere of Ukraine should obviously be considered a direct purposeful organizational-economic, scientific-educational and engineering-technological activity aimed at the formation of a knowledge society with an innovation-oriented type of economy of the state.

This includes:

- Accelerated formation of new knowledge, progressive innovative technologies, innovative resource sources, materials, means of production, forms of consumption and distribution of manufactured products and services.

- Ability to produce innovative products and services using global advanced technologies and advanced techniques (advanced techniques), which is becoming a dominant source of competitive advantage. An innovation-oriented economy is characterized by distinctive (special and distinct) producers and a high share of services in the economy and is sufficiently resistant to external influences. A distinctive feature of countries with an innovation-oriented economy is the production and export of new global knowledge (technologies, methods and techniques) necessary for the development of innovation and further socio-economic growth of countries).

Recall that the innovation-oriented stage of economic development of the state is characterized by an increase in entrepreneurial activity, including - an increase in the role of intellectual entrepreneurship. For over a century, there has been a tendency to increase the intellectual level of economic activity, which has been manifested in almost all industrialized countries, ranging from small firms to large organizations.

- Advance of intellectual capital. The world economic system of the late XX - early XXI centuries is characterized by a new paradigm of economic development based on a significant reduction in the role of material and resource components of social production and an increased role of the intellectual component. Knowledge production, distribution and use now form the basis of a knowledge-based economy, characterized by the growing interconnection between capital markets and emerging technologies, and the global nature of knowledge creation and use. In new economic conditions, purposeful formation of innovative potential, in- 
crease of intellectual capital and their competent use becomes the basis of economic growth.

- Formation of national human capital. The base of the knowledge society is a highly educated nation with specialists of the necessary level at all levels of functioning of the state system.

The main directions of innovative development of the sphere (system) of higher education include:

- Establishment of an "entrepreneurial mentality" in Ukrainian society through active promotion of entrepreneurial activity as a mechanism of self-realization of a person and creation of new jobs. The state support of all types of entrepreneurship as the main factor of economic growth of the state is necessary. Also it is needs a strengthening of economic and entrepreneurial education, teaching the basics of economic knowledge and entrepreneurship vocational training, courses of theoretic and practical training, practical life-long entrepreneurship training..

- Widespread introduction, with the state support of innovative "academic or university entrepreneurship", intellectual entrepreneurship, creation of legislative and regulatory acts to stimulate invention, development of research and development, implementation and commercialization of the results of scientific and technical activities.

- Giving broad (full) autonomy to universities of all types and forms of ownership.

- Strengthening the role of "science" of research universities.

- Integration of university science with academic and sectoral sciencefor example, on the basis of amalgamation or merger of HEIs with academic and sectoral research institutes, laboratories, etc. with the aim of forming educational and scientific associations, scientific parks and techno parks with the prospect of further cooperation with industry (business) and creation of techno-policies and educational-scientificindustrial entities (associations, scientific-grads, regional innovative educational-scientific-industrial complexes). Creation and development of incubators, spin-offs and start-ups of venture capital companies.

- Strengthening of the role of the state in support of the triad of society "University - Business - Government", where the core of innovation is the university, and each of the three institutions, in addition to its traditional functions, partially begins to fulfill the functions of others. Establishment of independent institutions for licensing and accreditation of HEIs activities. Creating new forms of budget financing for higher education and research, granting grants and public procurement solely on a competitive basis with the involvement of members of the public and the media.

The main stages in the implementation of innovative development of higher education include:

- Formulation and concretization of scientifically grounded innovative changes and directions of their implementation.

- Formation and concretization of scientifically grounded innovative changes and organizational principles of their implementation. 
- Science-based calculation of material costs for the introduction of innovative changes.

- Creating the necessary economic and organizational conditions for effective implementation of innovative changes.

- Realization of innovative changes, their constant updating and improvement.

Based on our studies as to world experience, it can be argued that major innovative changes in the higher education system can occur in objectively defined main areas. Next, let's look at the main directions in which innovative changes in higher education are taking place and the main (desired) results (see Fig. 1):

- New content of education: formation of a new content of education aimed at preparing a person for self-realization and independent living in society.

- New learning technologies: development, creation and implementation of innovative learning technologies; general and inclusive entrepreneurial and environmental education; training in life protection, IT and cyber security methods in all spheres of human activity.

- New curricula: use of methods, techniques, tools implementation of new curricula and plans.

- Comfortable conditions: creating comfortable conditions for self-determination in the learning process.

- Changes in the way they work and the way they think: Encouraging changes in the way they act and the way they think about teachers, students and students, changes in the relationship between them, creating and developing innovative teams in educational institutions at all levels.

- Educating interest in R\&D: educating young people with an interest in research and development by engaging in scientific and design work, striving for search, inventions and discoveries.

- Diversification of sources of financing, attraction of private capital: diversification of ways and sources of financing, search for new sources of financial support, creation of innovative funds of financial and economic and logistical support for education, wide involvement and use of private capital.

- Education (upbringing) of interest in academic (university) entrepreneurship, creation of conditions for entrepreneurship in HEI: education and stimulation of interest in academic (university) entrepreneurship by all members of the HEI team, commercialization of the results of educational, research and engineering activities, creation of the necessary conditions (logistical, legal, incentive and reward systems) for the motivation and practical implementation of educational, scientific, technical and technological entrepreneurship in HEI.

- Creation of organizational and legal conditions for commercialization of educational and scientific services and $R \& D$ results: creation of the necessary legal framework, support at the state level of measures for 
commercialization of the results of educational and scientific activities in the field of higher education, support of academic entrepreneurship.

- Dissemination of academic (university) entrepreneurship, innovative entrepreneurship-type HEIs, enhancement of the role of intellectual entrepreneurship in higher education as a factor of serious economic growth.

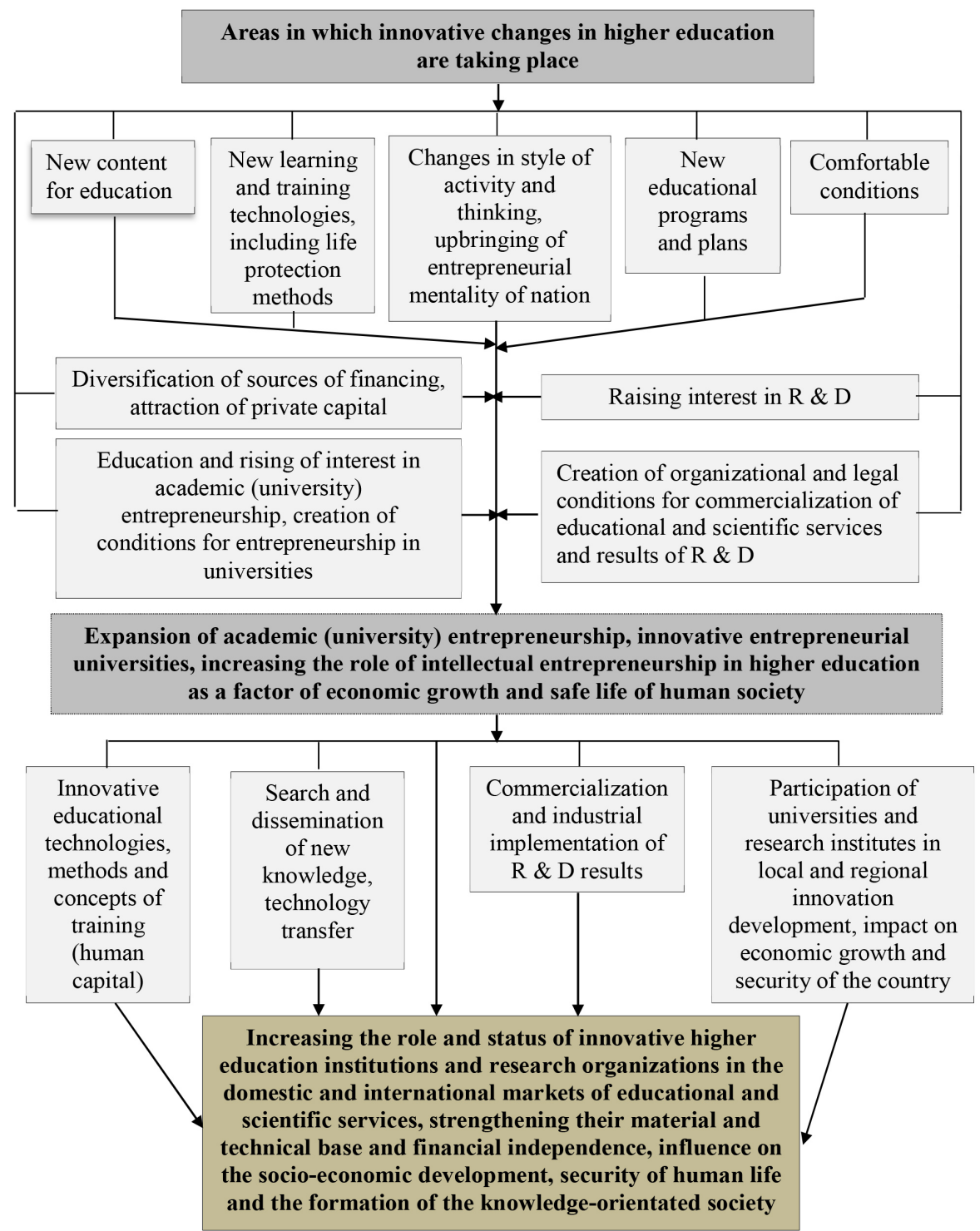

Fig. 1. Areas in which innovative changes in higher education are taking place and the main (desired) results 
The implementation of such innovative changes and transformational transformations in the higher education system should lead to:

- dissemination and promoting of innovative academic (university) entrepreneurship in the field of higher education;

- creation of innovative HEIs and business-type scientific institutions;

- enhancing the role of innovative intellectual entrepreneurship, linked to the production of innovative products, technologies and services through the use of new knowledge and based on high-level intellectual activity;

- accelerating the economic growth of the country and increase its competitiveness on the world stage.

The result of the active expansion of academic (university) entrepreneurship, the activities of innovative universities of entrepreneurial type, the enhancement of the role and importance of intellectual entrepreneurship in higher education should be:

- Innovative educational technologies, training methods and techniques.

- Search, acquisition and dissemination of new knowledge, technology transfer.

- Commercialization and industrial implementation of $\mathrm{R} \& \mathrm{D}$ results.

- Participation of universities and research institutes in local and regional innovation development influence on the economic growth and security of the state/country.

The most important results of such innovations are the enhancement of the role and status of innovative HEIs and research organizations in the domestic and international markets of educational and scientific services, strengthening their material and technical base and financial independence, influence on the socio-economic development, security of human life and the formation of the knowledge-orientated society.

Conclusion. Summarizing the results of a comprehensive study of the innovation in university education as a factor of sustainable development of Ukraine it is necessary to note the very slow reform of Ukrainian higher education and the lack of effective innovation. Ukraine needs the development and state legislative support of academic entrepreneurship. It is necessary to strengthen the cooperation of universities with the institutes of the NAS, as well as with business and the manufacturing sector. It is necessary to introduction of the institute of state (budgetary) and private (independent) project financing in the field of higher education, organization of state support for cooperation between universities and industry - according to the model of "Triple helix" by H.Etzkowitz [10-15].

As to the need for implementation and state support in academic or university entrepreneurship in Ukraine [5-13], it should be noted that entrepreneurial universities operate in the higher education system under the current market laws of the economic system, interact with the internal forces of the surrounding society (responding to its challenges and requests), are influenced by the globalization pressure of the world community. 
One of the most important functions of higher education in Ukraine is the development and providing of training programs on environmental management methods and protecting the lives of its citizens. Due to the weak development of IT and the insufficient use of modern cyber protection measures, the economy, banking, financial and other spheres of the country's life are under constant threat. In article [17] posits that the first approach to develop a culture of Cyber and Information Technology for Ukraine's overall economic and strategic security should begin with the development and implementation of Cyber Financial Crimes Mitigation training not only for students but also for the senior managers and executives of Ukrainian enterprises. Because Cyber Financial Crimes have the most direct impact to that group and they have the means to address it, they are the group who can impart a culture of IT and Cyber Security to Ukrainian society and leadership.

The theoretical foundations and practical provisions of innovation activity in the field of higher (university) education in Ukraine it is advisable to distinguish as a separate scientific direction in the sphere or system of higher education. Authors propose to introduce a new scientific direction in the sphere or system of higher education with a new scientific term - "Innovatics of higher education" or "higher education innovatics". By definition, the theoretical foundations and practical provisions of the new scientific direction in the sphere of higher education - the innovatics in higher education must include a complex of innovative changes in the inherent to higher education types of novate activities. The further development and improvement of the innovative scientific direction of higher education - the "innovatics in higher education" is also of interest and scientific sense.

\section{References}

[1] Governmental Strategies and Innovation in Higher Education. 1989 / Ed. Frans A. Van Vught, Michigan University, Jessica Kingsley Pub., 232 p. URL: https://books.google.com.ua/books/about/Governmental_Strategies_ and_Innovation_i.html?id=BYqdAAAAMAAJ\&redir_esc $=y$ [accessed Jan 14 2020].

[2] Blouin, R. A., et al. 2009. Roles of Innovation in Education Delivery / R. A. Blouin, W.H. Riffee, E. T. Robinson, D. E. Beck, C. Green, P. U. Joyner, A. M. Persky, G. M. Pollack. Am. J. Pharm. Educ. Dec 17, 73(8), 154 URL: https://www.ncbi.nlm.nih.gov/pmc/articles/PMC2828315 [accessed Jan 29 2020].

[3] Tierney, W. G., Lanford, M. 2016. Conceptualizing Innovation in Higher Education / W.G. Tierney, M. Lanford, M.B. Paulsen (ed.), Higher Education: Handbook of Theory and Research — Springer International Publishing Switzerland, 40 p. URL: https://www.researchgate.net/publication/ 303208037_Conceptualizing_Innovation_in_Higher_Education [accessed Jan 10 2020].

[4] OECD. 2016. Innovating Education and Educating for Innovation: The Power of Digital Technologies and Skills, OECD Publishing, Paris, $150 \mathrm{p}$. URL: http://www.oecd.org/education/ceri/GEIS2016-Background-document. pdf [accessed Jan 22 2020]. 
[5] Slaughter, S., Leslie, L. 1997. Academic capitalism. Politics, Policies, and the Entrepreneurial University / S. Slaughter, L. Leslie. - Baltimore, MA, U.S.A.: The John Hopkins University Press, 276 p.

[6] Slaughter, S., Rhoades, G. 2009. Academic Capitalism and the New Economy. Markets, State and Higher Education / S. Slaughter, G. Rhoades. U.S.A.: The Johns Hopkins University Press, 384 p.

[7] Clark, B.R. 1998.Creating Entrepreneurial Universities: Organizational Pathways of Transformations / B. R. Clark, Oxford: Pergamon-Elsevier Science, $180 \mathrm{p}$.

[8] Clark, B. R. 2000. Collegial Entrepreneurialism in Proactive Universities: Lessons from Europe / B. R. Clark // Change: The Magazine of Higher Learning, Vol. 32, Is. 1 (Jan/Feb), P. 10-19. URL: https://www. tandfonline.com/doi/abs/10.1080/00091380009602704 [accessed Feb 9 2019].

[9] Clark, B. R. 2004. Sustaining Change in Universities. Continuities in Case Studies and Concepts. The Society for Research into Higher Education \& Open University Press / B. R. Clark, SL6 2QL, England: McGrawHill, $232 \mathrm{p}$.

[10] Etzkowitz H. 2003. Innovation in Innovation: The Triple Helix of University - Industry - Government Relations. Social Science Information, Vol. 42, Is. 3, P. 293-337. URL: https://www.researchgate.net/publication/ 249733214_Innovation_in_Innovation_The_Triple_Helix_of_University-IndustryGovernment_Relations [accessed Jul 16 2019].

[11] Etzkowitz H. 2008. The Triple Helix: University - Industry - Government Innovation in Action / H. Etzkowitz. - New York \& London: Routledge, Taylor \& Francis Group, $164 \mathrm{p}$.

[12] The Age of Knowledge: The Dynamics of Universities, Science and Societies. 2012. Ed. H. Etzkowitz with Dzisah. Leiden: Brill, 360 p.

[13] The Capitalization of Knowledge: A Triple Helix of University - Industry Government. 2011. / Ed. H. Etzkowitz with Viale, Studies in Higher Education, Vol. 36, Is. 6, P. 746-747. URL: https://www.tandfonline.com/doi/ full/10.1080/03075079.2011.594602 [accessed May 12 2019].

[14] Etzkowitz, H. 2019. Is Silicon Valley a global model or unique anomaly? / H. Etzkowitz, Industry and Higher Education, Vol. 33, Is. 2, P. 83-95 URL: urlhttps://journals.sagepub.com/doi/abs/ 10.1177/0950422218817734 [accessed Jan 06 2020].

[15] Cadorin, E., Klofsten, M., Albahari, A., Etzkowitz, H. 2019. Science Parks and the Attraction of Talents: Activities and Challenges / E. Cadorin, M. Klofsten, A. Albahari, H. Etzkowitz // Triple Helix Journal, September 2019, P.1-33. URL: https://www.researchgate.net/publication/336278817_ Science_Parks_and_the_Attraction_of_Talents_Activities_and_Challenges [accessed Jan 29 2020].

[16] Grajek, S. 2020. How Colleges and Universities Are Driving to Digital Transformation Today / by S. Grajek, EDUCAUSE Review Special Report (January 27, 2020) URL: https://er.educause.edu/articles/2020/1/ how-colleges-and-universities-are-driving-to-digital-transformation-today [accessed Apr 20 2020].

[17] Debbins, P. 2019. Securing Ukraine through Cyber Financial Crimes Mitigation / P. Debbins // BESLI, Vol. 2019, Is. 3, P. 25-30. URL: https:// www.concordia.edu.ua/wp-content/uploads/2020/06/besli-volume-2019issue-003.pdf [accessed Jan 31 2020]. 